\title{
Preparation and Flame Retardant and Smoke Suppression Properties of Bamboo-Wood Hybrid Scrimber Filled with Calcium and Magnesium Nanoparticles
}

\author{
Bin Fu, Xingong Li, Guangming Yuan, Weimin Chen, and Yage Pan \\ Central South University of Forestry and Technology, Institute of Materials Science and Engineering, Changsha, \\ Hunan 410004, China \\ Correspondence should be addressed to Xingong Li; lxgwood@163.com
}

Received 22 April 2014; Revised 22 June 2014; Accepted 2 July 2014; Published 16 July 2014

Academic Editor: Jihua Gou

Copyright (C) 2014 Bin Fu et al. This is an open access article distributed under the Creative Commons Attribution License, which permits unrestricted use, distribution, and reproduction in any medium, provided the original work is properly cited.

The physical and mechanical properties of bamboo-wood hybrid scrimber filled with different loadings of nanoparticles were studied. The effects of nanoparticles on flame retardant and smoke suppression properties of bamboo-wood hybrid scrimber were studied by means of thermogravimetric analysis (TGA), cone calorimeter (CONE), and scanning electron microscope (SEM). The results showed that the physical and mechanical properties of bamboo-wood hybrid scrimber were improved by adding a moderate loading of nanoparticles; the optimal loading of nanoparticles was $10 \%$. The heat transfer in bamboo-wood hybrid scrimber was prevented and the escaping channel of combustible gas was blocked by the uniformly filling effect of nanoparticles. The gas concentration was diluted by the noncombustible gas produced by pyrolysis of nanoparticles; the combustion chain reaction was suppressed by highly reactive free radicals produced by pyrolysis of nanoparticles. The residual mass of bamboo-wood hybrid scrimber filled with nanoparticles in thermogravimetric (TG) curve at $900 \mathrm{~s}$ and burned by method of cone calorimeter (CONE) at $600 \mathrm{~s}$ was increased compared to that of untreated one, which showed that inorganic mineral powder has the effect of catalytic charring.

\section{Introduction}

The process of production of traditional wood particle board and fiber board deteriorated the natural wood texture and influenced the properties of raw materials. As for the bamboo based panels, there are a number of shortcomings including being hard to glue, difficult machining, and a low utilization rate of raw material $[1,2]$. The bamboo-wood hybrid scrimber which is prepared by different bamboo-wood hybrid ratio has high specific modulus and specific strength. Furthermore, it can not only keep the texture direction of raw material in a great extent, fully showing their respective advantages, but also reduce the production cost, increasing the value of the fast-growing timber $[3,4]$. Bamboo-wood hybrid scrimber can be widely used in furniture, flooring, and building materials industries; all these areas require products which are flame retardant. In recent years China has seen the frequency of fires increase. The resulting damages, in both life and property, has meant that research on the flame retardant and smoke suppression nature of bamboo-wood hybrid scrimber has become more and more important. Natural inorganic mineral powder has the advantages of being nontoxic, being noncorrosive, and being of cheap price. The channels which used for water absorption and free formaldehyde release can be blocked by a small amount of nanoparticles that filled in bamboo-wood hybrid scrimber, the physical and mechanical properties and environmental property of bamboo-wood hybrid scrimber can be improved as well $[5,6]$. Nanoparticles have the property of flame retardant; some nanoparticles also can be decomposed to produce noncombustible gases to block the smoke release channel in bamboo-wood hybrid scrimber at high temperature, that makes it have the function of flame retardant and smoke suppression. In recent years, reports of inorganic mineral powder research are mainly focused on the effect on physical and mechanical properties of materials, while this paper is about the preparation of 


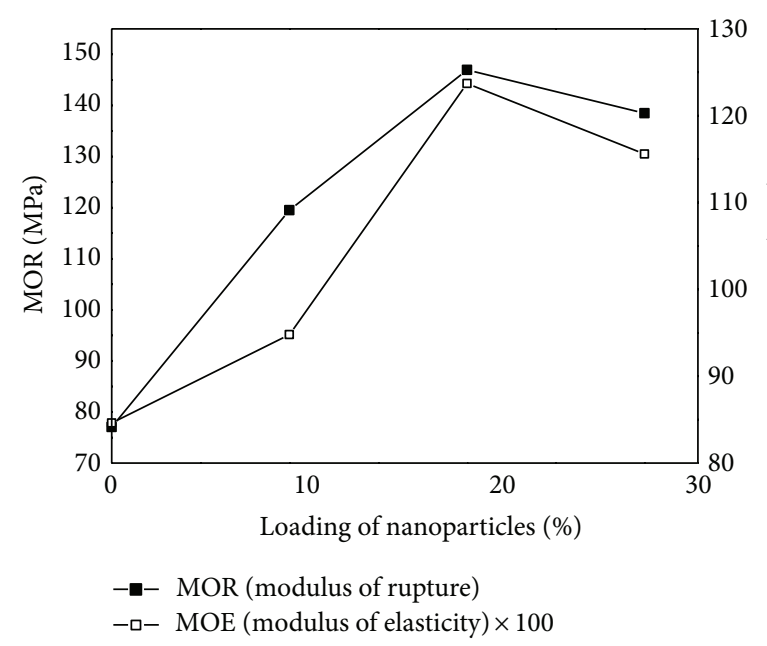

(a)

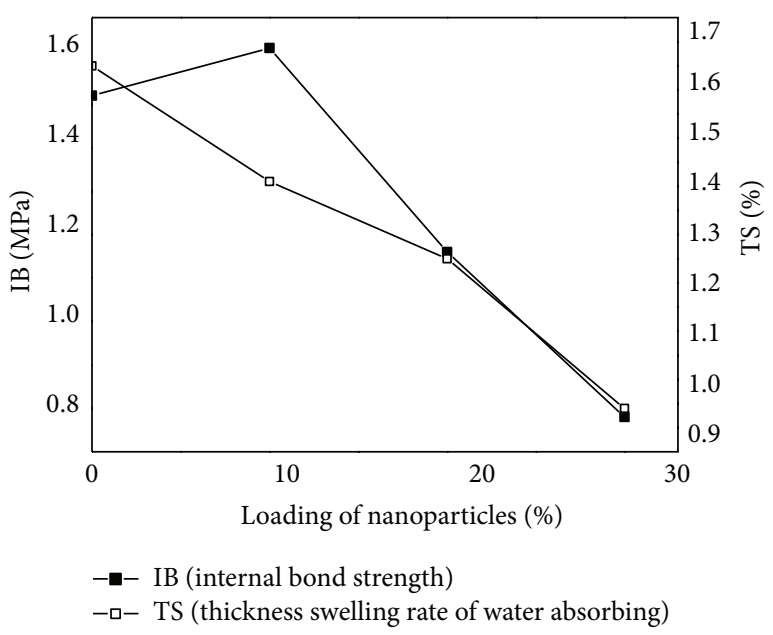

(b)

FIGURE 1: The physical and mechanical properties of bamboo-wood hybrid scrimber filled with different loadings of nanoparticles.

bamboo-wood hybrid scrimber made by bamboo, wood, and phenol formaldehyde resin (PF) and the effect of nanoparticles on the flame retardant and smoke suppression properties of bamboo-wood hybrid scrimber.

\section{Materials and Methods}

\subsection{Raw Materials}

Bamboo. From Taohuajiang bamboo industry Co., Ltd. in Yiyang Hunan province. Age of bamboo is 4-5 years old, diameter at breast height (DBH) is $60-80 \mathrm{~mm}$, thickness of bamboo wall is $3-5 \mathrm{~mm}$, and moisture content is around $12 \%$.

Eucalyptus. From Taohuajiang bamboo industry Co., Ltd. in Yiyang Hunan province. Moisture content is around $12 \%$.

Water-Soluble Phenolic-Formaldehyde Resin (PF). From Taohuajiang bamboo industry Co., Ltd. in Yiyang Hunan province. Appearance is brown red liquid, solid content is $51.2 \%$, viscosity is $280-360 \mathrm{mPa} \cdot \mathrm{s}\left(20^{\circ} \mathrm{C}\right)$, and $\mathrm{PH}$ is 10.53 .

Nanoparticles. Diameter is $5-50 \mathrm{~nm}$ and main ingredients are $\mathrm{CaCO}_{3}, \mathrm{CaO}, \mathrm{MgCO}_{3}$, and $\mathrm{MgO}$.

2.2. The Preparation and Performance Test of Bamboo-Wood Hybrid Scrimber. The bamboo-wood hybrid ratio was $3: 2$, solid content of adhesive was $25 \%$. Adding a certain amount of nanoparticles into the PF, stir evenly, put the bamboo strips and wood strips into the PF and completely soak it for $10 \mathrm{~min}$, then take them out, and put them into the drying oven for 3 hours under $60^{\circ} \mathrm{C}$ after there is no drop of glue liquid dropping out. Assembly pattern is achieved by "Bamboo layer-wood layer-bamboo layer" in a longitudinal uniform arranged way [7], the slab design density was $1.1 \mathrm{~g} / \mathrm{cm}^{3}$, size is $400 \times 250 \times 16 \mathrm{~mm}$, using hot pressing process in which the hot board comes in and the cold board goes out. Hot process temperature is $150^{\circ} \mathrm{C}$, hot process time is $1.5 \mathrm{~min} / \mathrm{mm}$, and unloading the plates temperature is $50^{\circ} \mathrm{C}$. For cone test, 5 specimens were tested for each sample and took the average.

Detection method on physical and mechanical properties of bamboo-wood hybrid scrimber was according to GB/T 7657.4-2003.

2.3. Thermogravimetric Analysis (TGA). Thermogravimetric (TG) and differential scanning calorimetry (DSC) analysis of the specimen were researched by STA449C thermobalance from NETZSCH Company in Germany. 10-15 mg samples powder was weighed in $\mathrm{Al}_{2} \mathrm{O}_{3}$ crucible; test temperature scope is $40^{\circ} \mathrm{C}-1000^{\circ} \mathrm{C}$; heating rate $(\beta)$ is $10^{\circ} \mathrm{C} / \mathrm{min}$, using $\mathrm{N}_{2}$ as shielding gas.

2.4. Cone Calorimeter (CONE). The specimen was researched by cone calorimeter (Stanton Redcroft), radiant heat flux is $50 \mathrm{KW} / \mathrm{m}^{2}$ which was close to the actual fire intensity $780^{\circ} \mathrm{C}$, specimen size is $100 \times 100 \times 10 \mathrm{~mm}$, and time to ignition (TTI) was recorded by man, using origin software for data processing.

2.5. SEM Analysis. The specimen was analyzed by scanning electron microscope quanta 450, and the specimen section was fixed and on the specimen stage by conducting carbon cloth rubber, flattened, and then dried on the heating plate; specimen surface was plated with $3 \mathrm{~nm}$ platinum by ion sputtering apparatus. Working voltage is $20 \mathrm{kV}$, accelerating current is $15 \mathrm{~mA}$, and working distance is $15 \mathrm{~mm}$.

\section{Results and Discussion}

3.1. The Effect on Physical and Mechanical Properties of Bamboo-Wood Hybrid Scrimber Filled with Different Loadings of Nanoparticles. Figure 1 is the physical and mechanical 


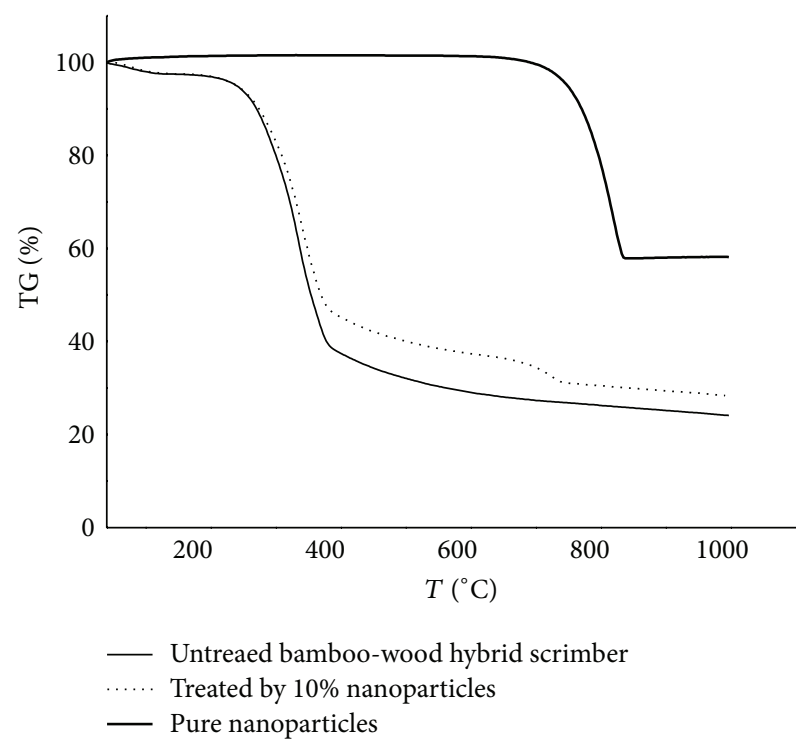

(a)

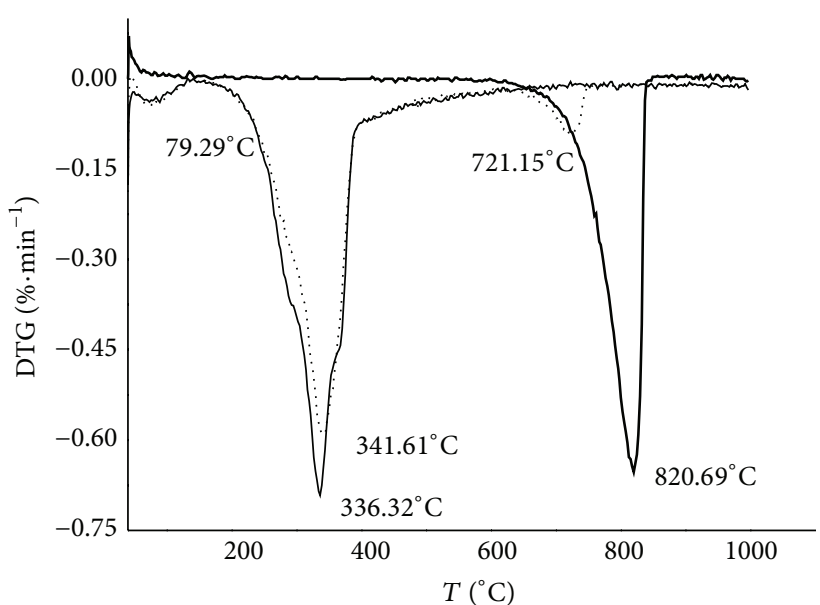

_ Untreated bamboo-wood hybrid scrimber
… Treated by $10 \%$ nanoparticles
_ Pure nanoparticles

(b)

FIgURE 2: The TG, DTG curves of bamboo-wood hybrid scrimber and nanoparticles.

properties of bamboo-wood hybrid scrimber filled with different loadings of nanoparticles; it shows that each mechanical property of bamboo-wood hybrid scrimber was improved by the treatment of $10 \%$ nanoparticles; Modulus of Rupture (MOR), Modulus of Elasticity (MOE), and Internal Bond (IB) strength were increased. Thickness Swelling (TS) rate of water absorbing was decreased. This is because nanoparticles was in a fine powder shape, nanoparticles can fill into the porosity of the bamboo-wood hybrid scrimber with the glue, then fix the glue into the porosity of the bamboowood hybrid scrimber. The whole plate becomes more closegrained, and organizational units junction increases; the local stress concentration was decreased, bonding strength become stronger, and moisture absorption channels can also be blocked by nanoparticles; this will improve the dimension stability of bamboo-wood hybrid scrimber $[8,9]$. Internal Bond strength of bamboo-wood hybrid scrimber will be decreased if the loading of nanoparticles was over $10 \%$; this is because nanoparticles have bad compatibility with the base. It is easy to de-bond the connection between rigid particles and base if the bamboo-wood hybrid scrimber was under external force because of the bad compatibility. Adhesives' unit effective components in the surface area of bamboo strip and eucalyptus strip are reduced owing to the excess nanometer inorganic mineral powder added in, and as a consequence of the weak boundary, layer was formed between bamboo strip and adjacent bamboo strip, bamboo strip and adjacent wood strip, and wood strip and adjacent wood strip $[10,11]$. Based on the analysis above, the optimal loading of nanoparticles was $10 \%$.

3.2. Thermogravimetric Analysis (TGA). Figure 2 is the thermogravimetric (TG) and derivative thermo gravimetric analysis (DTG) curve of bamboo-wood hybrid scrimber filled with $10 \%$ nanoparticles, untreated bamboo-wood hybrid scrimber, and pure inorganic mineral powder. The figure showed that the pyrolysis processing of bamboo-wood hybrid scrimber has experienced three stages of the loss of free water, pyrolysis, and the end of thermal decomposition of coke [12], while the pyrolysis processing of bamboo-wood hybrid scrimber filled with nanoparticles has experienced four stages of the loss of free water, pyrolysis, pyrolysis of nanoparticles, and the end of thermal decomposition of coke and pure nanoparticles have experienced just one stage of pyrolysis processing. Figure 2(b) showed that in the main pyrolysis stage, the DTG peak temperature of bamboo-wood hybrid scrimber filled with nanoparticles moves to slightly to higher temperature compared to untreated one and the size of DTG peak was reduced by $13.6 \%$ compared to the untreated one; all of these proved that nanoparticles can restrain the pyrolysis of bamboo-wood hybrid scrimber. The residual quantity of bamboo-wood hybrid scrimber filled with nanoparticles (remove $10 \%$ mineral powder quality after pyrolysis) was increased by $3.09 \%$ compared to untreated one at $900^{\circ} \mathrm{C}$, and this shows that bamboo-wood hybrid scrimber has the function of catalytic charring.

3.3. Cone Calorimeter (CONE). Table 1 is the main combustion characteristic data of bamboo-wood hybrid scrimber filled with nanoparticles and untreated one. Table 1 showed that time to ignition (TTI) of bamboo-wood hybrid scrimber filled with nanoparticles was lengthened compared to the untreated one. This is because the incombustibility nanoparticles distributed on the surface of bamboo-wood hybrid scrimber delayed the time to burn. The residual quality of bamboo-wood hybrid scrimber filled with nanoparticles increased by $30.07 \%$ compared to untreated one after $600 \mathrm{~s}$ of combustion. This showed that bamboo-wood hybrid scrimber has the function of catalytic charring. This result is in line with the TG results. 
TABLE 1: The main combustion characteristic data of bamboo-wood hybrid scrimber (radiant heat flux $50 \mathrm{~kW} / \mathrm{m}^{2}$ ).

\begin{tabular}{lccccrr}
\hline Sample & $\begin{array}{c}\text { TTI } \\
(\mathrm{s})\end{array}$ & $\begin{array}{c}M_{600} \\
(\%)\end{array}$ & $\begin{array}{c}\text { pk-HRR1 }\left(t_{1}\right) \\
\left(\mathrm{kW} \cdot \mathrm{m}^{-2}\right)\end{array}$ & $\begin{array}{c}\text { pk-HRR2 }\left(t_{2}\right) \\
\left(\mathrm{kW} \cdot \mathrm{m}^{-2}\right)\end{array}$ & $\begin{array}{c}\text { a-SEA } \\
\left(\mathrm{m}^{2} \cdot \mathrm{kg}^{-1}\right)\end{array}$ & $\begin{array}{c}\text { pk-SEA1 }\left(t_{1}\right) \\
\left(\mathrm{m}^{2} \cdot \mathrm{kg}^{-1}\right)\end{array}$ \\
\hline Untreated one & 30 & 29.40 & $198.23(75 \mathrm{~s})$ & $272.11(555 \mathrm{~s})$ & 83.07 & $519.54(25)$ \\
Treated by 10\% nanoparticles & 37 & 38.24 & $178.46(65 \mathrm{~s})$ & $184.41(585 \mathrm{~s})$ & 55.62 & $398.89(20)$ \\
\hline
\end{tabular}

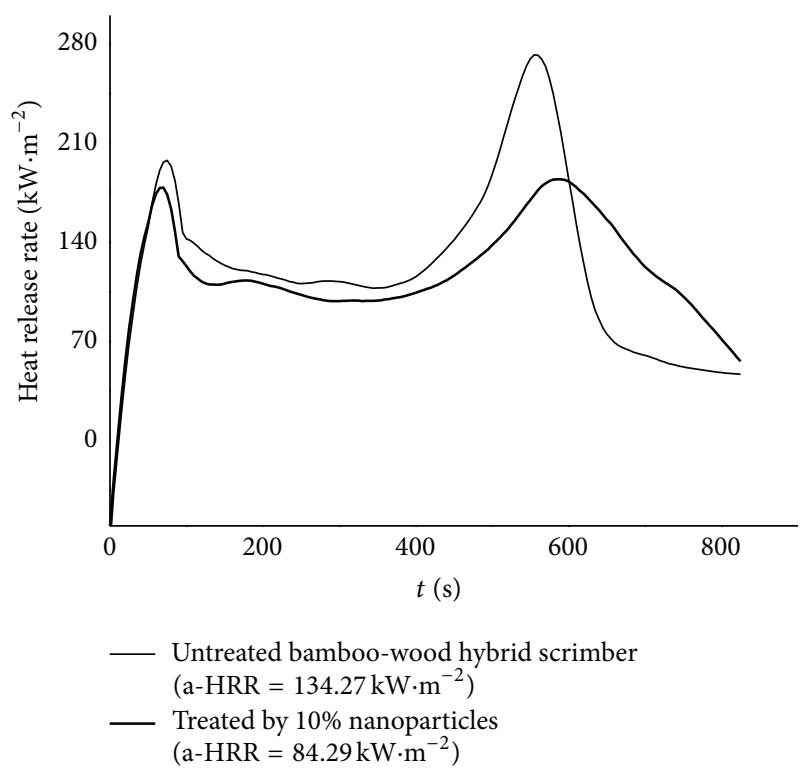

FIGURE 3: The HRR curves of bamboo-wood hybrid scrimber.

Figures 3 and 4 are heat release rate (HRR) curve and total heat release (THR) curve of bamboo-wood hybrid scrimber filled with nanoparticles and untreated one. From Figure 3, Figure 4, and Table 1 we can know that the average heat release rate (a-HRR) and the quantity of total heat release (THR) of bamboo-wood hybrid scrimber filled with nanoparticles were decreased by $37.22 \%$ and $33.19 \%$ compared to untreated one, and two peaks of heat release rate of bamboo-wood hybrid scrimber filled with nanoparticles were decreased by 9.97\% and 32.23\%; this showed that combustion exothermic reaction in bamboo-wood hybrid scrimber can be restrained by nanoparticles, and that is because nanoparticle has the flame retardant property and a low heat transfer coefficient, uniformly distributed in the bamboo-wood hybrid scrimber to prevent heat from transferring and block the escape channel of combustible volatiles produced by the process of bamboo-wood hybrid scrimber pyrolysis. Nanoparticles contain a large amount of $\mathrm{CaCO}_{3}$ and $\mathrm{MgCO}_{3}$, decomposition reaction is endothermic reaction at high temperature, so they will absorb the heat around to decrease the temperature of the surface and burned area, and carbon dioxide produced by decomposition can dilute the concentration of combustible gas and oxygen around to suppress the combustion. A large amount of highly reactive free radicals $\mathrm{HO}^{\bullet}$ and $\mathrm{H}^{\bullet}$ produced by the combustion of bamboo-wood hybrid scrimber are closely related to the speed of combustion, nanoparticles decomposed at high temperature, and free radicals were

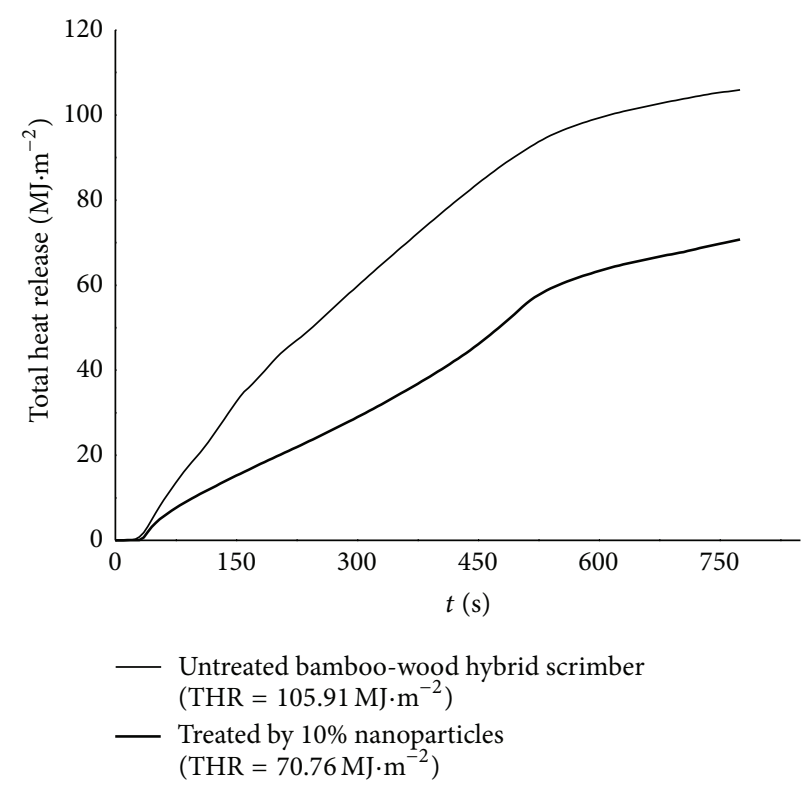

FIgURE 4: The THR curves of bamboo-wood hybrid scrimber.

produced by chemical bond rupture. These free radicals reacted with highly reactive free radicals $\mathrm{HO}^{\circ}$ and $\mathrm{H}^{\circ}$, so the combustion chain reaction was suppressed by highly reactive free radicals [13].

Figure 5 is the total smoke rate (TSR) curve of bamboowood hybrid scrimber filled with nanoparticles and untreated one. Figure 5 and Table 1 show that TSP of bamboo-wood hybrid scrimber filled with nanoparticles was decreased by $29.47 \%$ compared to untreated bamboo-wood hybrid scrimber after $900 \mathrm{~s}$ of combustion, the values of average extinction area (a-SEA) was decreased by $33.04 \%$, this proved that bamboo-wood hybrid scrimber filled with nanoparticles has the function of smoke suppression, and that is because nanoparticles blocked the escape channel of smoke in bamboo-wood hybrid scrimber.

3.4. SEM Analysis (SEM). Figures 6 and 7 are the carbon residue SEM figure of untreated bamboo-wood hybrid scrimber and bamboo-wood hybrid scrimber filled with nanoparticles. Figure 6 showed that the charcoal layer of the untreated bamboo-wood hybrid scrimber after combustion was cracked and was in a loose shape. This is because a large sum of the smoke produced by combustion inside has impact to the material itself; after charcoal layer cracked, heat and oxygen are easy to enter inside with the combustible gas coming out, and it is a threat for the material used for retarding fire. Figure 7 showed that nanoparticles are 


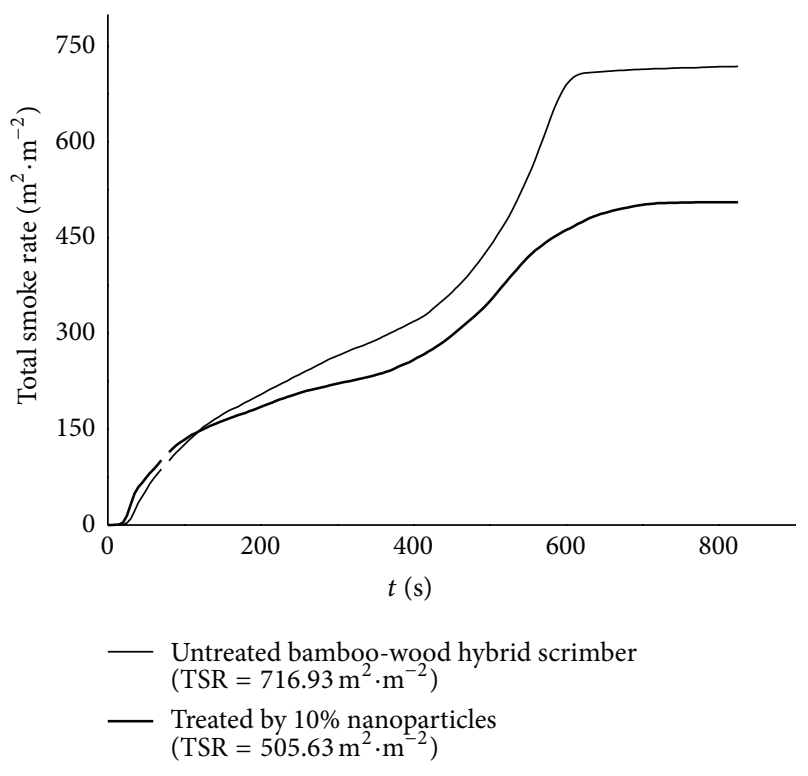

FIGURE 5: The TSR curves of bamboo-wood hybrid scrimber.

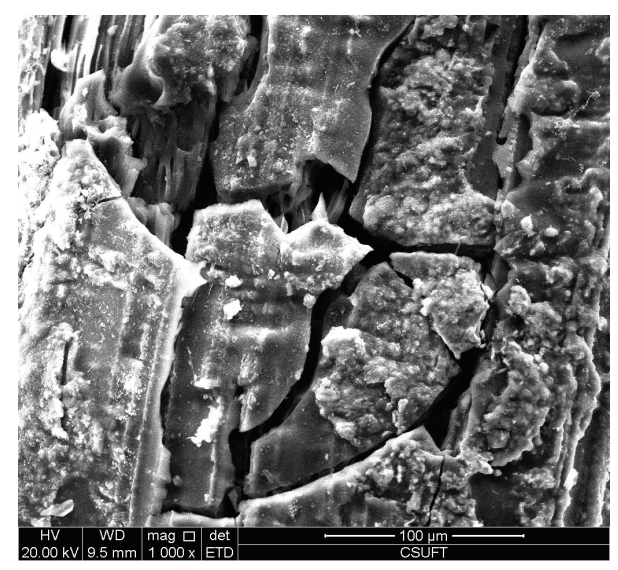

FIgURE 6: The carbon residue SEM figure of untreated bamboowood hybrid scrimber.

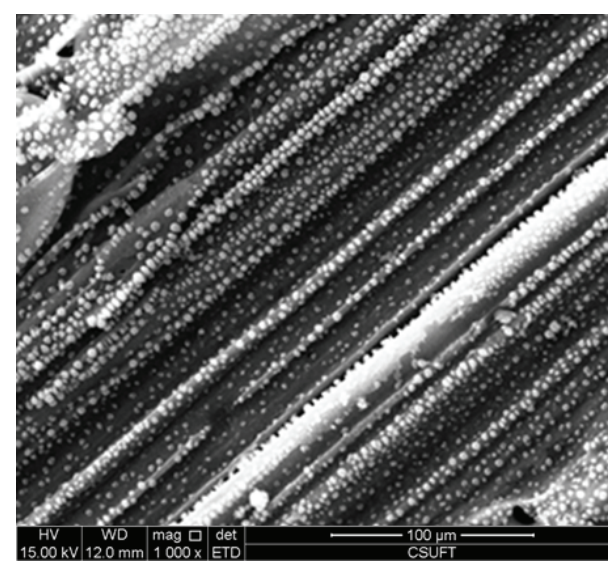

FIGURE 7: The carbon residue SEM figure of bamboo-wood hybrid scrimber filled with nanoparticles. uniformly distributed in the charcoal layer of bamboowood hybrid scrimber, residual coal surface of bamboo-wood hybrid scrimber filled with nanoparticles was dense and was regularly arranged after combustion; that is because the hard $\mathrm{CaO}$ and $\mathrm{MgO}$ produced by decomposition of $\mathrm{CaCO}_{3}$ and $\mathrm{MgCO}_{3}$ formed a coating on the surface of material to inhibit the release of combustible gas and smoke and isolate oxygen from outside [14], as well as preventing the heat transfer. $\mathrm{CaO}$ and $\mathrm{MgO}$ have flame retardant properties, uniformly distributing in the bamboo-wood hybrid scrimber to prevent the heat from transferring and block the escape channel of the combustible gas.

\section{Conclusions}

(1) The physical and mechanical properties of bamboowood hybrid scrimber were improved by adding a moderate loading of nanoparticles; the optimal loading of nanoparticles was $10 \%$.

(2) Bamboo-wood hybrid scrimber thermal weight loss maximum rate's temperature can be improved by the nanoparticles, the numerical of thermal weight loss maximum rate was decreased as well, and it has the function of restraining the pyrolysis of bamboo-wood hybrid scrimber. The residual quantity of bamboowood hybrid scrimber filled with nanoparticles was increased, and it has the function of flame retardant and catalytic charring. Residual coal surface of bamboo-wood hybrid scrimber filled with nanoparticles was dense and was regularly arranged after combustion; this kind of construction inhibited the release of combustible gas and smoke and isolated oxygen from outside, as well as preventing bamboowood hybrid scrimber to burn.

(3) The heat transfer in bamboo-wood hybrid scrimber was prevented and the escaping channel of combustible gas was blocked by the uniformly filling effect of nanoparticles. The gas concentration was diluted by the noncombustible gas produced by pyrolysis of nanometer inorganic mineral powder, and the combustion chain reaction was suppressed by highly reactive free radicals produced by pyrolysis of nanometer inorganic mineral powder.

\section{Conflict of Interests}

The authors declare that there is no conflict of interests regarding the publication of this paper.

\section{Acknowledgments}

Xingong Li would like to thank and appreciate all authors for their valued contributions and to all potential reviewers for sparing their valuable time, efforts, and constructive comments for this special issue. This work is supported by the following foundation items: the National Natural Science Foundation (31370569), the Hunan major science and technology projects (2011FJ1006), and the major scientific 
research projects of Public Welfare Profession of national forestry (201204702).

\section{References}

[1] N. Nugroho and N. Ando, "Development of structural composite products made from bamboo I: Fundamental properties of bamboo zephyr board," Journal of Wood Science, vol. 46, no. 1, pp. 68-74, 2000.

[2] L. Qin and H. Xiqi, "The development and prospect ion of reconsolidated bamboo," Journal of Bamboo Research, vol. 20, no. 1, pp. 76-80, 2001.

[3] Z. Jiang, G. Wang, B. Fei, and W. Yu, "The research and development on bamboo-wood composite materials," Forest Research, vol. 15, no. 6, pp. 712-718, 2002.

[4] M. Ahmad and F. A. Kamke, "Analysis of Calcutta bamboo for structural composite materials: physical and mechanical properties," Wood Science and Technology, vol. 39, no. 6, pp. 448-459, 2005.

[5] P. Jie, L. Bin, and W. Zhaobo, "The study on flame retardant performance of composite," Function Materials, vol. 16, no. 9, pp. 9-11, 2012.

[6] B. Li, "Influence of polymer additives on thermal decomposition and smoke emission of poly(vinyl chloride)," Polymer Degradation and Stability, vol. 82, no. 3, pp. 467-476, 2003.

[7] G. Donglan, The Study on Key Technology and Performance of Bamboo-Wood Hybrid Scrimber, Nanjing University, Nanjing, China, 2008.

[8] N. Nugroho and N. Ando, "Development of structural composite products made from bamboo I: fundamental properties of bamboo zephyr board," Journal of Wood Science, vol. 46, no. 1, pp. 68-74, 2000.

[9] M. Ahmad and F. A. Kamke, "Analysis of Calcutta bamboo for structural composite materials: surface characteristics," Wood Science and Technology, vol. 37, no. 3-4, pp. 233-240, 2003.

[10] K. Ghavami, "Bamboo as reinforcement in structural concrete elements," Cement and Concrete Composites, vol. 27, no. 6, pp. 637-649, 2005.

[11] A. W. C. Lee, X. Bai, and A. P. Bangi, "Selected properties of laboratory-made laminated-bamboo lumber," Holzforschung, vol. 52, no. 2, pp. 207-210, 1998.

[12] W. Lihua, W. Shurong, and L. Zhongyang, "Biomass multicomponent pyrolysis kinetics of model," Journal of Zhejiang University (Engineering Science), vol. 2, no. 39, pp. 247-251, 2005.

[13] Z. Jianjun, Z. Jinzong, and J. Quan, "The study on Burning performance and flame retardant mechanism of the MWNTsOH/PET nanocomposites," Function Materials, vol. 1, no. 24, pp. $2-3,2010$.

[14] Z. Weiping, Z. Guangzhong, and Z. Zejun, "The effect on combustion smoke of PVC with acid radical ion," Chinese Plastics, vol. 14, no. 6, pp. 59-62, 2010. 

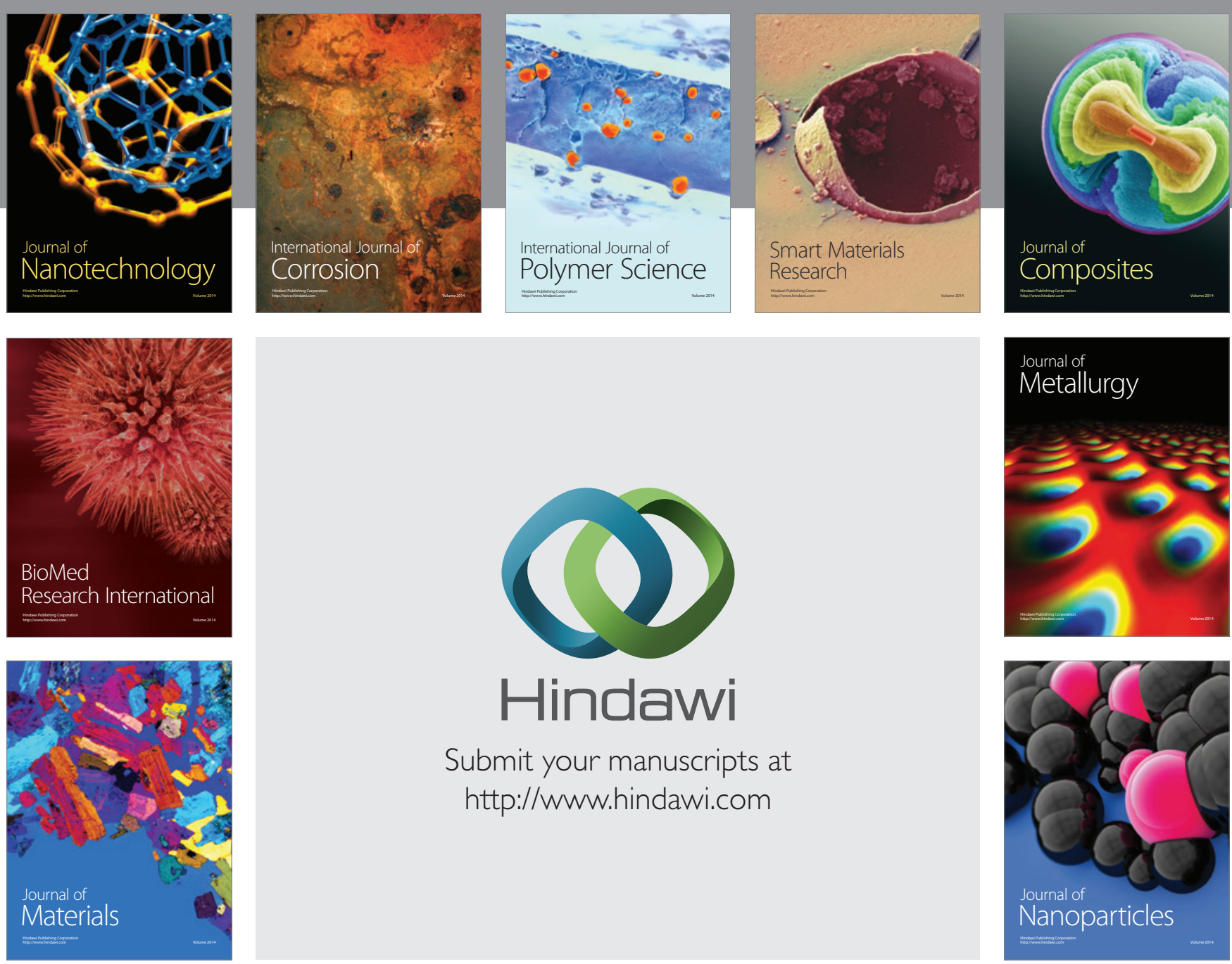

Submit your manuscripts at http://www.hindawi.com
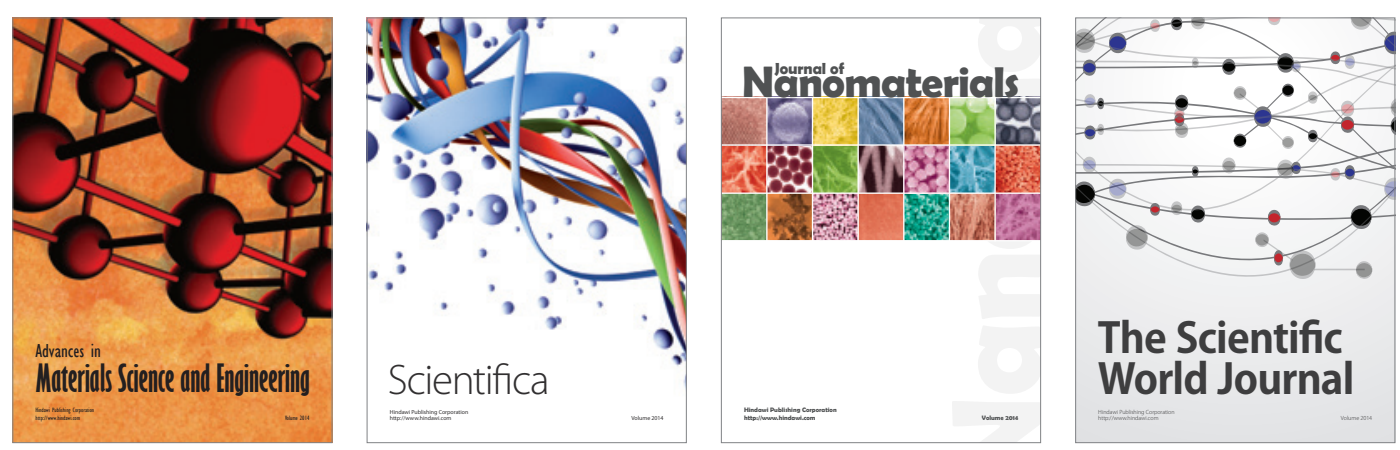

\section{The Scientific World Journal}
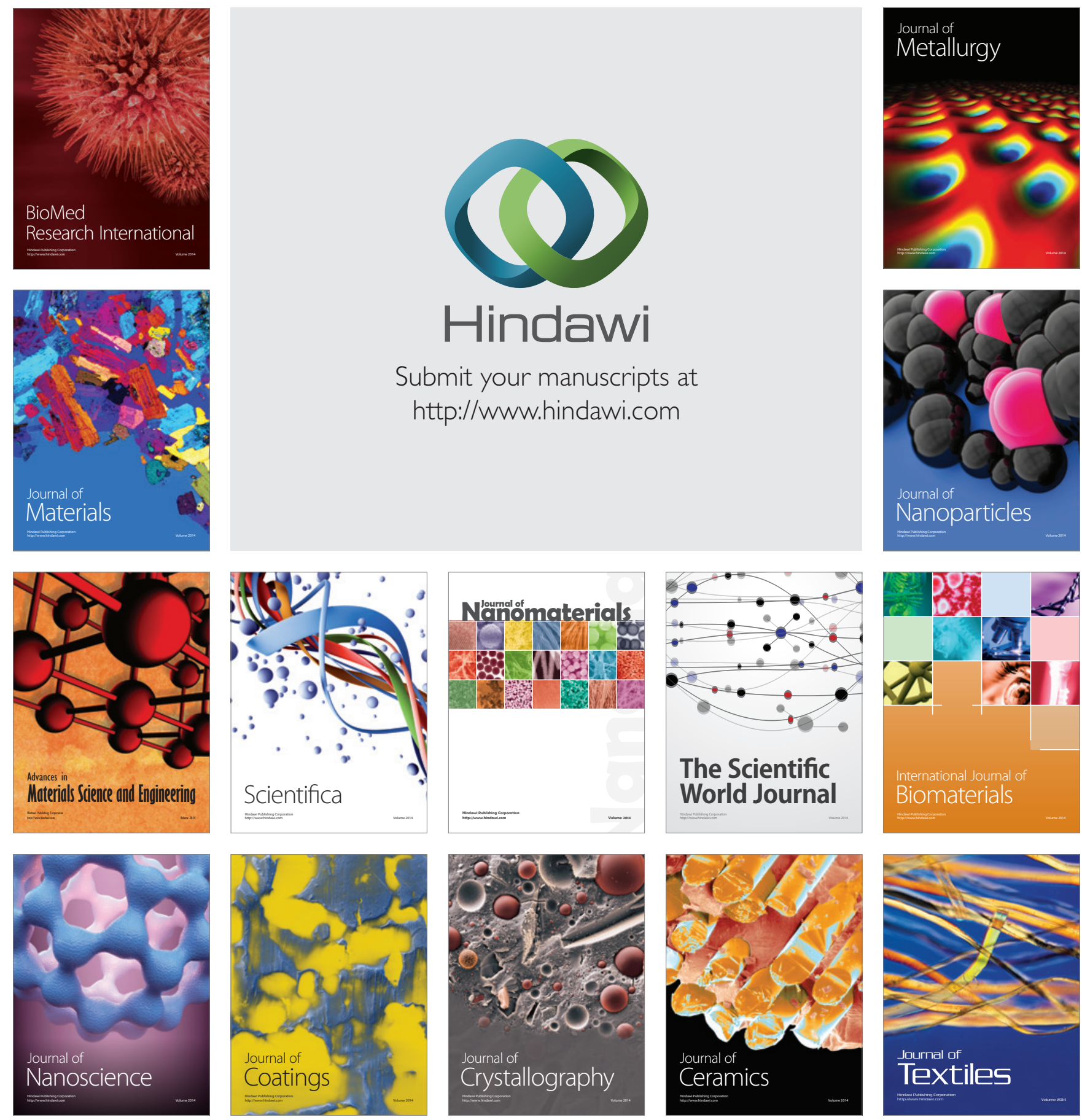